\title{
AN INTRODUCTION TO THE AEPS-3 AND RESULTS OF A FIELD TEST STUDY
}

\author{
JoAnn (JJ) Johnson ${ }^{1}$, \& Marisa Macy ${ }^{2}$ \\ ${ }^{1}$ Dr., School of Education, Child and Family Studies, St Cloud State University (USA) \\ ${ }^{2}$ Dr., School of Teacher Education, Early Childhood Development \& Education Program/University \\ of Central Florida (USA)
}

\begin{abstract}
The AEPS, a curriculum-based, criterion-referenced programmatic assessment tool was developed to collect developmental progress information, primarily of children with disabilities, from birth through age five. First published in 1993 (birth through age two) and 1995 (age three through five) and again in 2003 ( $2^{\text {nd }}$ edition), the tool was designed to determine a child's repertoire of skills and to identify next skills needed for developmental progress. One important aspect of the tool was the one-to-one correspondence of assessment and curriculum items. Needed skills identified in assessment, were then matched with the same curriculum skills and provided users with tiered strategies and suggestions to support the child with multiple activity-based practice opportunities. A variety of additional components were available to support using the AEPS and monitoring progress. Components' use was optional and consisted of the AEPS Family Report with both qualitative and quantitative questions, Progress Report, Assessment Activities, IFSP and IEP examples, programming steps, and Social Communication Observation and Summary Forms. Additionally, cut scores were established in 2006 that permitted use of the AEPS to corroborate eligibility, and in 2007 to determine eligibility for early intervention/special education services.

The AEPS is considered one of the most functional assessment tools published for use with young children with disabilities. The second edition consists of 455 items, with 248 in Level I (birth through two) and 217 in level 2 (three through five), with approximately 250 programming steps, for children making more incremental progress. Currently, AEPS $2^{\text {nd }}$ edition has been published in Spanish, Canadian French, Korean, Finnish, and Traditional Chinese.

In 2007 a third edition of the AEPS was begun. Changes included consolidating levels into a seamless test (birth through six), adding literacy and math areas, including science items, refinement of test/curriculum items, thorough criteria, improved AEPS components to the $3^{\text {rd }}$ edition, and importantly, a new curriculum. The AEPS-3 curriculum is divided into three levels; beginning, growing and ready. Each curriculum level includes numerous daily activities and routines with practice opportunities for all items.

The AEPS-3 was field tested by 125 teachers with prior AEPS experience, administered to approximately 300 children, to evaluate its psychometric properties; specifically, inter-rater reliability, utility, and concurrent validity. This presentation will 1) report the field study results and introduce AEPS-3's major components; and 2) discuss implications of using a technically sound tool with the diverse ethnicities and cultural backgrounds of children and their families.
\end{abstract}

Keywords: AEPS, assessment, curriculum, children, progress.

\section{Introduction}

Early childhood assessment procedures are guided by recommended practices from a variety of sources (Division of Early Childhood, 2014; Jiban, 2013; National Association for the Education of Young Children, 2009). Across sources, there is agreement early childhood assessments should be socially valid, use authentic assessment methods, allow for collaboration between families and professionals, have evidence that supports their reliability and validity, and be sensitive to child change over time. The type of assessment tools matching these recommended practices most closely are curriculum-based assessments (CBAs). According to Grisham-Brown \& Pretti-Frontczak (2011), a curriculum-based assessment contains test items that are aligned with the curriculum so what is on the test can actually be taught. Many curriculum-based assessments are also criterion-referenced, meaning the test's purpose is to measure a child's performance over time by determining the extent to which a child meets the criterion or standard 
for each item on the test. Curriculum-based assessments are primarily used to assist teachers/providers/interventionists in knowing what to teach. When working with young children who have disabilities, data from a CBA are used to identify individual goals or outcomes for the child's Individualized Education Plan (IEP) or Individualized Family Service Plan (IFSP) based on current and next skills. Moreover, CBAs show a child's progress over time, as children are compared to themselves and not to a normative sample of same age peers. CBAs have been used to report children's progress as part of state and federal accountability systems (Grisham-Brown, Pretti-Frontcak, \& Hallam, 2008).

One early childhood instrument used by many early childhood providers is the Assessment, Evaluation, and Programming System for Infants and Children Test (AEPS). The AEPS, a curriculum-based, criterion-referenced programmatic assessment tool was developed to collect developmental progress information, primarily of children with disabilities, from birth through age five. Work on AEPS started in the 1970s. First published in 1993 (birth through age two) and 1995 (age three through five) and again in 2003 ( $2^{\text {nd }}$ edition), the tool was designed to determine a child's repertoire of skills and to identify next skills needed for developmental progress. One important aspect of the tool was the one-to-one correspondence of assessment and curriculum items. Needed skills identified in assessment, were then matched with the same curriculum skills and provided users with tiered strategies and suggestions to support the child with multiple activity-based practice opportunities. In 2007 a third edition of the AEPS was begun. Changes included consolidating levels of the tool into a seamless test (birth through six), adding literacy and math areas, and including science items to the assessment and curriculum. AEPS is now in its third edition and includes the following areas:

- Math (new),

- Literacy (new),

- Adaptive,

- Cognitive,

- Fine motor,

- Gross motor,

- Social Emotional, and

- Social Communication

The AEPS-3 assessment is also linked to an early childhood curriculum for children birth to age six. The AEPS-3 curriculum is divided into three levels; beginning (infant/toddler), growing (toddler/preschooler) and ready (preschooler). Each curriculum level includes daily activities and routines with numerous embedded practice opportunities for all items.

AEPS-3 also offers a graduated scoring mechanism. AEPS-3 is designed to capture changes when used more than once and over time. A three-point rating scale allows the user to determine the level of skill acquisition for a wide range of items which includes: mastery, emerging, or not yet. An online data management system called AEPSi assists in the use of the curriculum-based assessment (Macy, 2010).

A variety of additional components are available to support using the AEPS and monitoring child progress. AEPS-3 components' use is optional and consists of the AEPS-3 Family Report and the Family Assessment of Child Skills (FACS) with both qualitative and quantitative sections, a Child Progress Record, Assessment Activities for both home and center-based services, IFSP and IEP examples, Foundational Skills leading to objectives and goals, and Social Communication Observation and Summary Forms. Additionally, cut scores are currently being established that permit professionals use of the AEPS to corroborate and determine eligibility for EI/ECSE services (Bricker et al., 2003, 2008).

AEPS Family Report and the Family Assessment of Child Skills enables collaboration between professionals and children's families and can be used as a portfolio to monitor progress. Accountability in EI/ECSE programs can also be monitored using the AEPS-3. The AEPS-3 Ready-Set is a tool for professionals to use as children transition into Kindergarten settings.

The AEPS is considered one of the most functional assessment tools published for use with young children with disabilities. The third edition consists of 407 items, with 225 foundational skills, for children making more incremental progress. The AEPS $2^{\text {nd }}$ edition has been published in Spanish, Canadian French, Korean, Finnish, and Traditional Chinese. The AEPS-3 has, thus far, been translated and is being published in Spanish, Canadian French, and Traditional Chinese (see Implications and Future Directions).

\section{Purpose}

The purpose of the field test study was to evaluate the psychometric properties of the third edition of AEPS. Specifically, the study examined the inter-rater reliability, utility, and concurrent validity of AEPS-3. 


\section{Methodology}

$\underline{\text { Subjects }}$

- Teachers:

$\mathrm{n}=116$ for interrater agreement;

$\mathrm{n}=11$ for utility;

$\mathrm{n}=8$ for concurrent validity

Children:

$\mathrm{n}=23$ for utility

$\mathrm{n}=50$ for concurrent validity

children with and without disabilities

Procedures

- Utility:

Teachers completed AEPS-3 on 2-3 children and completed a utility survey consisting of items about Scoring, Items and Criteria, and Usefulness of AEPS-3 for Intended Purpose.

- Interrater Agreement:

Teachers were required to watch an online training on changes to AEPS. Following training, they watched 37 videoclips that contained 68 items from the AEPS-3. After observing the video, they were asked to score items using the 2, 1, 0 scoring system of AEPS-3

- Concurrent Validity:

Teachers, trained in both the Battelle Developmental Inventory (Newborg, 2005) and the AEPS-3 administered both assessments to the same children within two weeks of each other.

\section{Results: concurrent validity}

Table 1. Correlation Results for AEPS-3 Domain Scores and BDI-2 Domain Scores $(N=50)$.

\begin{tabular}{|c|c|c|c|c|c|c|}
\hline & \multicolumn{5}{|c|}{ BDI-2 Domain } & \multirow[b]{2}{*}{$\begin{array}{r}\text { Age } \\
\text { (in mor }\end{array}$} \\
\hline $\begin{array}{l}\text { AEPS-3 } \\
\text { Domain }\end{array}$ & Adaptive & Cognitive & Communication & Motor & $\begin{array}{l}\text { Personal- } \\
\text { Social }\end{array}$ & \\
\hline $\begin{array}{l}\text { Adaptive } \\
(\alpha=.55)\end{array}$ & $.40 * *$ & $.46 * *$ & $.57 * *$ & $.33^{*}$ & $.41 * *$ & $.92 *$ \\
\hline $\begin{array}{l}\text { Cognitive } \\
(\alpha=.66)\end{array}$ & $.41 * *$ & $.50 * *$ & $.62 * *$ & $.33 *$ & $.48 * *$ & $.86^{*}$ \\
\hline $\begin{array}{l}\text { Fine Motor } \\
(\alpha=.39)\end{array}$ & .24 & $.31 *$ & $.45^{* *}$ & $.32 *$ & $.36 * *$ & $.65^{*}$ \\
\hline $\begin{array}{l}\text { Gross Motor } \\
(\alpha=.61)\end{array}$ & $.34 *$ & $.46^{* *}$ & $.57 * *$ & $.44 * *$ & $.38 * *$ & $.72 *$ \\
\hline $\begin{array}{l}\text { Literacy } \\
(\alpha=.70)\end{array}$ & $.50 * *$ & $.60 * *$ & $.65 * *$ & $.44 * *$ & $.50 * *$ & $.89 *$ \\
\hline $\begin{array}{l}\text { Math } \\
(\alpha=.70)\end{array}$ & $.41 * *$ & $.55 * *$ & $.62 * *$ & $.32 *$ & $.42 * *$ & $.87^{*}$ \\
\hline $\begin{array}{l}\text { Social } \\
\text { Communication } \\
(\alpha=.77)\end{array}$ & $.44 * *$ & $.48 * *$ & $.63 * *$ & $.35 *$ & $.52 * *$ & $.85^{*}$ \\
\hline $\begin{array}{l}\text { Social } \\
\text { Emotional } \\
(\alpha=.63)\end{array}$ & $.49 * *$ & $.54 * *$ & $.64 * *$ & $.42 * *$ & $.57 * *$ & $.80^{*}$ \\
\hline
\end{tabular}

\section{Results: interrater reliability}

Interrater reliability, results reveal teachers and experts agreement ranged from $66 \%$ to $100 \%$ with a mean of $89 \%(n=116)$. Participants could take the test multiple times to meet the $80 \%$ criterion required prior to collecting AEPS-3 field test data; the majority of participants met the $80 \%$ criterion correct on their first try (i.e., $89.79 \%$ ). 


\section{Results: utility}

A utility study was completed prior to collecting any other AEPS-3 field test data. The purpose was to gather information about the tool from a small sample of field test participants (11) to: 1) gain an understanding of the utility of the tool from established providers in the field, and 2) ensure there were no concerns with AEPS-3 test content and scoring.

Utility study participants were required to complete AEPS-3 online training prior to collecting assessment data; each participant completed their assessment on at least one child. Together the 11 participants assessed 23 children between ages of 4 and 83 months. Assessment data were collected in each 12-month age interval, and observations took place in the child's home or classroom setting.

A Utility Survey, consisting of questions about scoring, dimensionality of goals in all developmental areas and usefulness of the AEPS-3 for its intended purpose, was completed by the 11 participants after conducting AEPS-3 assessments. The Utility Survey consisted of 3 sections: I) Scoring, II) Items and Criteria, and III) Usefulness for Intended Purposes. Questions were rated on a 4-point Likert scale with 4= Strongly Agree and 1=Strongly disagree.

Section I included 13 questions about the 3-point scoring options $(2,1,0)$ and scoring notes (A = Assistance; $\mathrm{I}=$ Incomplete; $\mathrm{C}=$ Conduct; $\mathrm{M}=$ Modification; $\mathrm{Q}=$ Quality; and $\mathrm{R}=$ Report) of AEPS-3. Participants rated questions related to understanding score options $(\mathrm{M}=3.45)$ and if they permitted accurate rating $(\mathrm{M}=3.54)$. Participants rated scoring note options related to ease of understanding $(M=3.36)$ and enhanced accuracy in rating of child performance $(M=3.18)$. Participants also rated clearness of each scoring option description and knowing when to add the scoring notes. All items were rated above 82\% (Agree), and most items were rated above 91\% (Strongly Agree).

Section II asked participants to rate all AEPS-3 goals from the 8 developmental areas on a 4 point Likert scale on four dimensions: functionality, teachability, easy to understand goal and easy to understand criterion. Participants rated the majority of AEPS-3 goals as strongly agree or agree across all four dimensions. Four developmental areas met this criteria on all items: Adaptive, Literacy, Social-Communication, and Social-Emotional. The remaining four areas (Fine Motor, Gross Motor, Cognitive and Math) each had one item that fell below the Agree criteria.

Section III asked participants, using the 4 point Likert scale to rate the AEPS-3's intended purposes for use (authentic environments, information for summarizing strengths and present levels of development, reporting to state and federal agencies, monitoring child progress, and use of scoring notes I -incomplete and/or A - assistance for scoring 1), its use for progress monitoring, time needed to complete the AEPS-3, and their perspective on the strengths and weaknesses of the tool. For all Section III questions at least 9 participants indicated strongly agree or agree that AEPS-3 is useful for its intended purposes.

Based on participant survey results, no changes were made to the 3-point scoring options or the scoring notes. More examples of the scoring notes were provided in the training materials. Few changes were required in AEPS-3 items: one item was removed from the Literacy area and eight items were revised across Developmental Areas. Additionally, examples were revised or expanded to help further clarify test items. Specifically, the findings from the utility study showed that participants found the AEPS-3 useful from assessment and program planning to intervention and progress monitoring.

\section{Implications and future directions}

Future directions of AEPS could focus on: (1) increasing cultural and linguistic diversity, and (2) exploring the utility of the new areas -literacy and math. In terms of improving cultural and linguistic diversity, current AEPS items and examples are flexible for adaptations; however, some practitioners have reflected certain examples reflect "western culture." Thus, more non-cultural specific examples, as well as recommendations for cultural and linguistic adaptations are included in the new edition to help users from diverse backgrounds. Further directions could examine intervention strategies best matched to the AEPS-3 (Johnson et al, 2014).

Considering the diverse ethnicities and cultural backgrounds of children and their families in the U.S., and for countries that encounter challenges in finding a technically sound assessment tool, one solution is to select from existing tools with well-established psychometric properties and make culturally appropriate adaptations (Bornman, Sevcik, Romski, \& Pae, 2010; Heo \& Squires, 2012). Currently, AEPS has been published in Spanish, Canadian French, Korean, Finnish, and Traditional Chinese. The Simplified Chinese translation is under development. The Canadian French version has five studies examining its psychometric properties (Dionne, Bricker, Harguindéguy-Lincourt, Rivest, \& Tavarès, 2001; Dionne et al., 2015; Lemire, Dionne, \& McKinnon, 2014, 2015; Nader-Grosbois, Dionne, Rivest, \& Boutet, 2010). The Korean version has one study (Noh \& Park, 2008) where researchers examined how AEPS helped improve the quality of IEP goals and objectives. 


\section{References}

Bricker, D., Capt, B., Johnson, J., Pretti-Frontczak, K., Slentz, K., Straka, E., \& Waddell, M. (2002) AEPS: Assessment, Evaluation, and Programming System for Infant and Children, Volumes 1, 2, 3, 4 $\left(2^{\text {nd }}\right.$ Ed). Baltimore, MD: Paul Brookes.

Bricker, D., Yovanoff, P., Capt, B., Allen, D. (2003) Use of a curriculum-based measure to corroborate eligibility decisions. Journal of Early Intervention. Sage, 26 (1), 20-30.

Bricker, D., Clifford, J., Yovanoff, P., Pretti-Frontczak, K., Waddell, M., Allen, D., Hoselton, R. (2008) Eligibility determination using a curriculum-based assessment: A further examination. Journal of Early Intervention. Sage, 31 (1), 3-21.

Bornman, J., Sevcik, R., Romski, M., \& Pae, H. (2010). Successfully translating language and culture when adapting assessment measures. Journal of Policy and Practice in Intellectual Disabilities 7(2), 111-118

Dionne, C., Bricker, D., Harguindéguy-Lincourt, M., Rivest, C., \& Tavarès, C. (2001). Presentation of an assessment and intervention tool for young children: integrated system for child assessment, intervention, evaluation and programming (AEPS). Francophone Review of Intellectual Deficiency, Vol 12, (1), 21-29.

Dionne, C., Bricker, D., Harguindéguy-Lincourt, M., Rivest, C., \& Tavarès, C. (2015). Presentation d'un outil d'evaluation et d'intervention pour jeunes enfants. Francophone Review of Intellectual Deficiency, Vol 12, (1), 21-29.

Grisham-Brown, J, \& Pretti-Frontczak, K. (2011) Assessing young children in inclusive settings: The Blended Practices Approach. Baltimore, MD: Paul Brookes.

Grisham-Brown, J., Pretti-Frontcak, K., \& Hallam, R. (2008). Preparing Head Start Personnel to use a curriculum-based assessment: An innovative practice in the "Age of Accountability". Journal of Early Intervention 30(4), 271-281.

Grisham-Brown, J., Waddell, M., Crawford, R. and Toland, M. (in press). Psychometric Properties of the Assessment, Evaluation, and Programming System for Infants and Children, $3^{\text {rd }}$ Edition (AEPS-3). Journal of Early Intervention.

Heo, K. \& Squires, J. (2012). Cultural adaptation of a parent completed social emotional screening instrument for young children: Ages and Stages Questionnaire-Social Emotional. Early Human Development 88(3) 151-8.

Johnson, J., Rahn, N., \& Bricker, D. (2014). Activity-Based Intervention (ABI) $4^{\text {th }}$ ed. Baltimore, MD: Paul Brookes.

Lemire, C., Dionne, C., \& McKinnon, S. (2014, 2015). The use of authentic assessment to report accountability data on young children's language, literacy and pre-math competency. Revue de psychoeducation, vol 44 (1), 63-81.

Macy, M., Bricker, D., \& Squires, J. (2005). Validity and reliability of a curriculum-based assessment approach to determine eligibility for Part C services. Journal of Early Intervention, 20 (1), 1-16.

Macy, M., Bagnato, S. (2010). Keeping it R-E-A-L with authentic assessment.. National Head Start Association Dialog: A research-to-practice Journal for the Early Intervention Field 13 (1), 1-21.

Nader-Grosbois, Dionne, Rivest, \& Boutet, (2010). Implementation of the EIS program with stakeholders of the CRDITED de la Mauricie and the Center-du-Quebec-Institut Unvesitaire. Conference Paper, presented at $21^{\text {st }}$ Annual Thematic Symposium of the Quebec Institiute of Intellectual Disabilities. Oxford. QC

Newborg, J. (2005). Battelle Developmental Inventory. Saint Charles, IL: Riverside Publishing.

Noh, J. A., \& Park, H. J. (2008). The effects of curriculum-based assessment on the individualized education plan goals and objectives of young children with developmental delays. The Korean Journal of Early Childhood Special Education, 8(2), 17-37. 